\title{
EL BESTIARIO DEL EMPIORADOR. NOTAS SOBRE LA CARICATURA REPUBLICANA DURANTE LA INTERVENCIÓN Y EL SEGUNDO IMPERIO
}

\author{
Alejandro de la Torre Hernández \\ Instituto Nacional de Antropologia e Historia
}

$\mathrm{E}^{1}$ 1 actor principal de la caricatura política es el poder, sujeto medular de la interlocución y la denuncia política. Ya sea enjuiciando las medidas gubernamentales, satirizando las acciones de los presidentes, caricaturizando a los ministros, los diputados o los funcionarios públicos; ya caracterizando moralmente las políticas públicas, o esbozando críticamente los rasgos de la situación social, los poderes del estado están siempre ahí, representados bajo un registro mordaz que enjuicia sin piedad sus acciones.

En el contexto mexicano, desde la guerra de Reforma hasta los años ochenta del siglo xix, la defensa del proyecto republicano y la lucha por el poder definieron la orientación y los contenidos de la caricatura política. Durante la intervención francesa y el imperio, la prensa satírica de raigambre liberal cerró filas en torno a la causa de la República y la defensa del territorio nacional, produciendo imágenes

Fecha de recepción: 7 de enero de 2015

Fecha de aceptación: 20 de abril de 2015 
de combate que escarnecían al ejército invasor y al ultramontanismo nacional, en el marco de una prolongada confrontación política y simbólica. En el trasfondo de esta enconada disputa, lo que estaba en juego era la definición de la nación, articulada en torno a dos proyectos antagónicos que marcaron los términos del debate político a lo largo de todo el siglo xix: el liberalismo y el conservadurismo. El papel de la caricatura en este debate resultó de gran importancia para el proyecto liberal republicano, pues se constituyó como un espacio de reproducción de cultura política desde donde podían moldearse (y difundirse) visualmente imaginarios y proyectos políticos desde fuera del poder.

En estas páginas se emprende un veloz recorrido por la prensa política con caricaturas, en el que se trata de mostrar el recurso a un conjunto de criaturas monstruosas o zoomorfas, por medio de las cuales se pretendía develar la naturaleza moral de los gobernantes, de la clase política o de la situación social en su conjunto, poniendo en juego una serie de arquetipos y lugares comunes para caracterizar la contextura moral de los invasores y los defensores del proyecto imperial, en beneficio de un imaginario que se asumía nacionalista y republicano. Apelando a fuentes de inspiración que incluyen la mitología, el fabulario, las diversiones públicas o los cuadros de costumbres, se conformó una colección de retratos y alegorías que constituyen un auténtico compendio de teratología política, en cuyas imágenes se insiste en la denuncia del ejercicio del poder mal encauzado.

Con el triunfo de la revolución de Ayutla, dio inicio una nueva etapa para la prensa mexicana. Derrotado Santa Anna, reapareció la prensa libre y, con ella, los periódicos con caricaturas que, aprovechando los nuevos espacios abiertos para 
la interpelación política, no tardaron en hacer sentir su crítica al nuevo régimen republicano. ${ }^{1}$ Pero se trataba de una crítica tolerada por el gobierno por una cuestión de principios y de legitimidad política: la prensa libre era concebida como un componente crucial del pensamiento liberal, cuya ardua misión consistía nada menos que en mitigar (y llegado el caso sustituir) el control de la institución eclesiástica sobre las conciencias de los ciudadanos. De manera que la prensa libre se constituyó en una herramienta política fundamental en la constitución de la naciente república liberal.

La turbulencia política de mediados del siglo XIX ocasionó que la libertad de imprenta no fuera muy duradera. Asonadas, pronunciamientos y golpes de estado hicieron que la libertad de prensa, estipulada en el artículo $7^{\circ}$ de la Constitución de 1857, fuera observada de manera irregular. Durante la Guerra de Tres Años quedó suspendida definitivamente. Sin embargo, es en ese periodo en el que se considera que se vivió el florecimiento de la gran prensa liberal de combate y, por extensión, de la caricatura política, eficaz instrumento de propaganda y difusión de idearios políticos. ${ }^{2}$ Por ejemplo, fue la época en que salió a la luz el célebre periódico La Orquesta, dirigido por Carlos Casarín e ilustrado por el no menos célebre Constantino Escalante.

Desde las páginas de este periódico se criticaba severamente la conducción de la política económica puesta en práctica durante la presidencia de Juárez, así como las divisiones dentro de su gabinete y la ineptitud de quienes

\footnotetext{
${ }^{1} \mathrm{Al}$ respecto véase BARAjAs, La historia, pp. 57 y 188. Este autor señala que uno de los primeros objetivos de la crítica fue la inasistencia de los diputados a un Congreso en el que no se paraban "ni las moscas".

2 Barajas, La historia, p. 63.
} 
formaban parte del gobierno. Sin embargo, amén este implacable ejercicio crítico, La Orquesta enfilaba todo el rigor de su sátira contra un enemigo al que se consideraba más poderoso y temible: el bando conservador. Constantemente ridiculizado en sus pretensiones monárquicas y su ímpetu desestabilizador del país, auspiciado por una institución eclesiástica ansiosa de recuperar los privilegios del antiguo régimen, el conservadurismo fue tratado con ingenioso sarcasmo por la prensa satírica de orientación liberal, a pesar de sus manifiestas diferencias con el gobierno juarista.

Las críticas que desde La Orquesta se efectuaban contra el gobierno de Juárez disminuyeron de manera considerable cuando la intervención militar europea empezó a vislumbrarse como una posibilidad concreta. Para 1862, con el ejército francés desembarcando en Veracruz, La Orquesta cerró filas en torno al gobierno declarándole la guerra al invasor. ${ }^{3}$ Así, durante la etapa inicial de la intervención francesa, la crítica ejercida desde la prensa satírica tuvo como blancos principales a los invasores, a Napoleón III y a los conservadores mexicanos que secundaban el proyecto intervencionista e imperial.

En este contexto, Juan Nepomuceno Almonte y Alphonse Dubois de Saligny fueron inicialmente los personajes en los que se cebó la sátira republicana. El primero, hijo de José María Morelos, fue retratado con áspero desprecio por la caricatura política, en calidad de traidor a la patria, indigno de su insigne ancestro; mientras que el segundo, ministro de

${ }^{3}$ En mayo de 1862, en el contexto del triunfo en la Batalla de Puebla, se deslizaba en un editorial de La Orquesta: "D. Benito, aquel, el presidente, que ya va encontrando el modo de hacerse querer de nosotros...". “Orquesta”, en La Orquesta, 5 (14 mayo 1862). 
Francia en México, fue sistemáticamente escarnecido como un diplomático inescrupuloso, excesivamente aficionado a los placeres de Baco. En ambos casos, la caricatura política, la canción popular y la versada satírica se conjugaron en la elaboración de despiadados retratos morales que los representaban como sujetos despreciables, merecedores del encono popular. ${ }^{4}$

En este contexto, a principios de mayo de 1862, La Orquesta publicó una litografía de Escalante en la que se ve un conjunto de aves de rapiña con cabeza humana, a manera de arpías, que junto con Almonte se congrega a las puertas de una tienda de campaña, en cuyo interior se encuentra Saligny junto con otro personaje. Uno de los pajarracos lleva un pliego de papel en el que puede leerse: Pronunciamiento de la mayoría oprimida, mientras que otra de las aves lleva en la cabeza un sombrero de copa, en probable alusión a su origen aristocrático [Imagen 1].

La imagen satiriza la proclamación de Almonte como presidente de México, con el reconocimiento del imperio francés. De acuerdo con la orientación política de la caricatura, las aves de rapiña denotan la voracidad y la astucia de quienes secundaban este proyecto conservador, exhibiendo con ello la calidad moral de los personajes que veían con

\footnotetext{
${ }^{4}$ Sobre la manifiesta ojeriza que la sátira liberal le profesara a Almonte véanse los ejemplos citados por Mendoza, “Algunas canciones". Llama la atención que en las canciones que cita Mendoza, el eje argumental de la sátira enfatiza la procedencia indígena de Almonte puesta en contraste con las pretensiones aristocráticas de su proyecto político. En la caricatura política asistimos a un tratamiento análogo, de acuerdo con el cual, el vástago del "Siervo de la Nación" suele representarse con huaraches y calzón de manta, acompañado de su inseparable huacal, al tiempo que se ridiculiza frecuentemente su mal castellano.
} 


\section{Imagen 1}

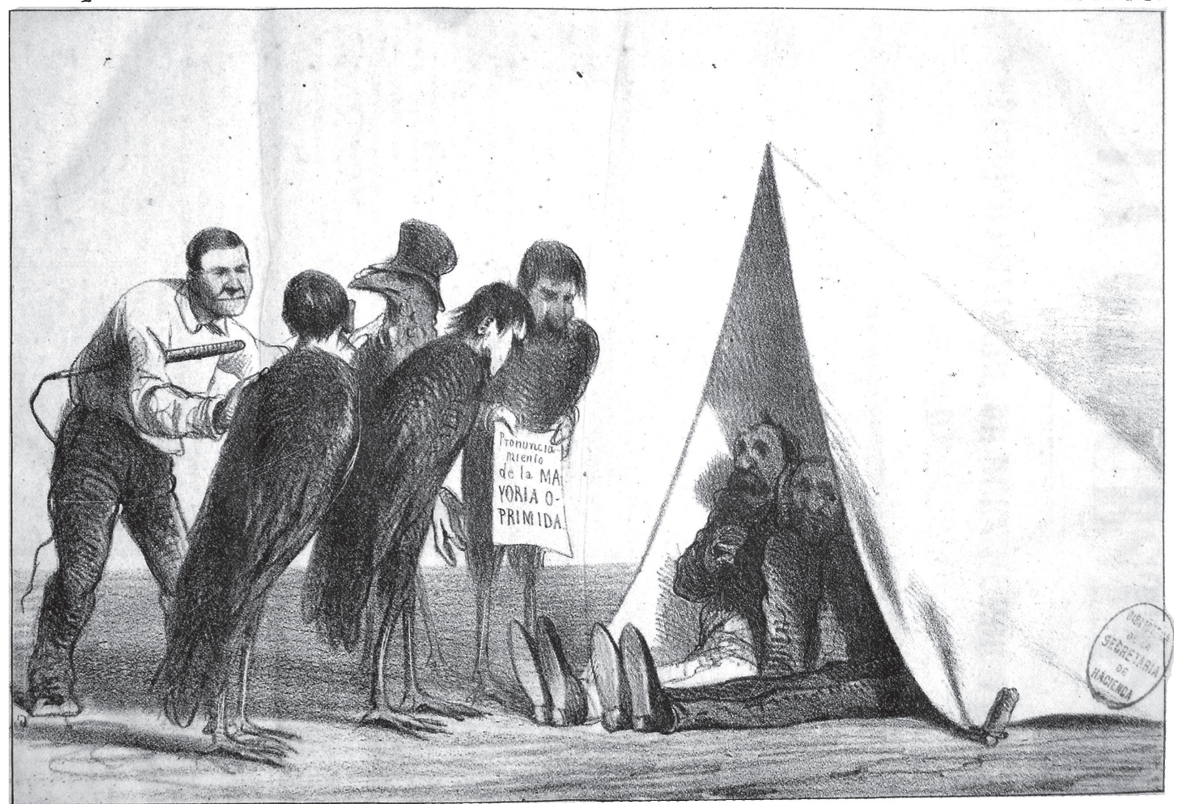

Los 9 r notables de Orizavá, prescrilan su acta de pronunciamiento a los Comisarios. Franceses.

Constantino Escalante, "Los 91 notables de Orizava [sic] presentan su acta de pronunciamiento a los Comisarios Franceses”, en La Orquesta (3 mayo 1862). 
simpatía la intervención francesa. El pronunciamiento al que se alude en la imagen se refiere a la rebelión generalizada que supuestamente tendría lugar en contra de Benito Juárez a la llegada del ejército invasor, expectativa que no se cumplió. Cabe decir que los conservadores, velando por sus intereses, se consideraban a sí mismos como una mayoría oprimida por el gobierno republicano, que veía la intervención como una posibilidad de recuperarse políticamente. Bajo esta óptica, y apoyándonos en el texto al pie de la imagen, la caricatura adquiere otra implicación propagandística, pues bien pudiera retratar no solo las aspiraciones presidenciales de Almonte, sino que exhibe también a la totalidad de esa mayoría conformada por "los 91 notables de Orizaba" y que es caracterizada por la rapiña y el oportunismo.

Paralelamente, para alentar la resistencia a la invasión, $\mathrm{La}$ Orquesta ridiculizó también a los soldados franceses. Un par de semanas después de la publicación de la caricatura que tenía por protagonistas a Almonte y su camarilla de arpías, salió a la luz otra caricatura, también de Escalante, en la que el ejército invasor era caracterizado como un puñado de patos con sombreros zuavos [Imagen 2]. Los palmípedos emprenden el vuelo desde un huacal (con el rótulo Intervención) que lleva en la espalda un sorprendido Juan Nepomuceno Almonte ataviado como indígena. Detrás de él, el general Lorencez, montando un burro mirando hacia las ancas del animal, sostiene una gran bota militar como trofeo de guerra ${ }^{5}$. Al fondo de la escena los

\footnotetext{
${ }^{5}$ Se trata de la bota que perdió el general Arteaga en la defensa de Acultzingo, "único trofeo que los liberales conceden hasta entonces al invasor"; Barajas, La historia, p. 214.
} 


\section{Imagen 2}

\section{LA ORPUESTA N. 5 .}

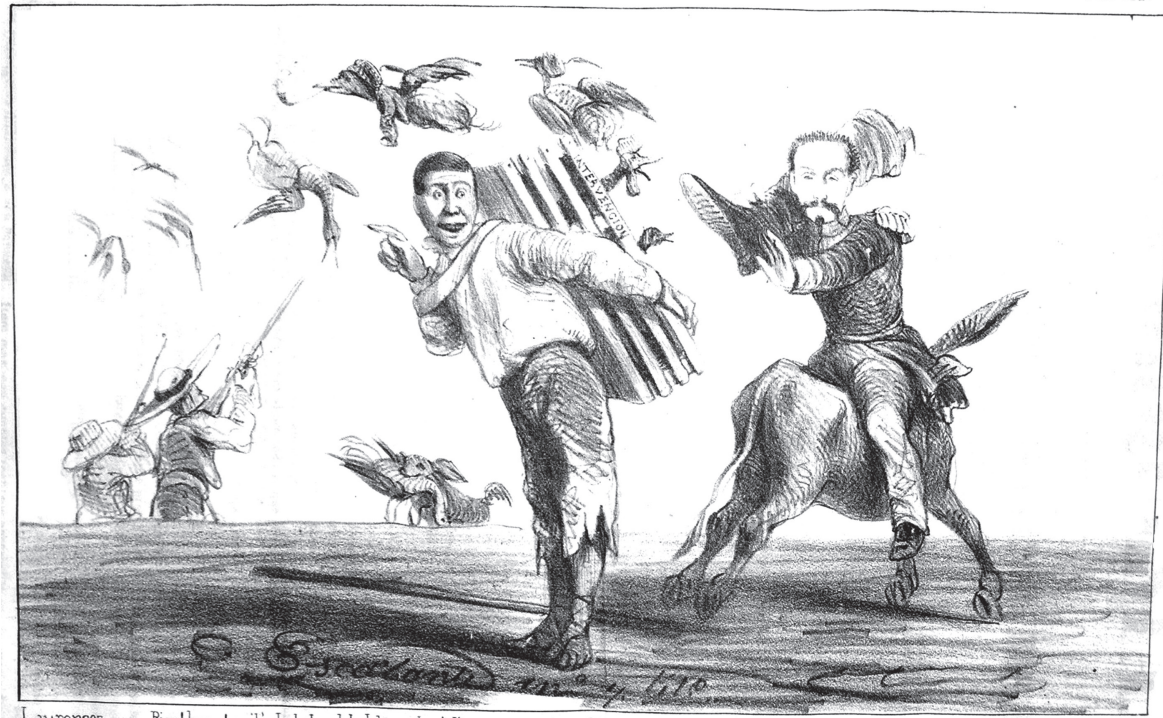

Laurencez - Bien! brava! voilá La bola del Lleneral Artiaja, cuyo frofeo Ilevo por Paris.

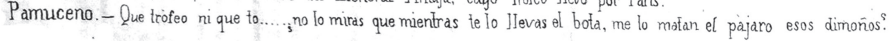

Constantino Escalante, en La Orquesta (14 mayo 1862). 
patos/zuavos son cazados al vuelo por un par de personajes ataviados a la usanza de los chinacos, que representan a las fuerzas republicanas.

La caricatura está imbuida del optimismo ocasionado por el reciente triunfo republicano del 5 de mayo en la ciudad de Puebla, y parece destinada a infundir confianza en la victoria definitiva de las armas nacionales. Minimiza el poderío del ejército invasor, al tiempo que acentúa la ineptitud de los mandos militares franceses y sus aliados mexicanos. Siguiendo la lógica de la imagen, los soldados galos son presa fácil para los chinacos de certera puntería; Almonte figura como el impulsor de una empresa militar de poca monta, aparentemente destinada al fracaso, mientras que Lorencez, aferrado a un exiguo botín, no atina a dirigir las acciones militares. Decía un verso alusivo a esta ilustración, publicado en el mismo número de La Orquesta:

$$
\begin{aligned}
& \text { Pero ¡ay! de la intervención } \\
& \text { en Guadalupe se estrella } \\
& \text { sin dejar de sí más huella } \\
& \text { que su vana presunción! } \\
& \text { Pamuceno en la derrota } \\
& \text { lloraba como un muchacho, } \\
& \text { pero Laurençez en su macho }^{\text {cargando siempre la bota. }}{ }^{6}
\end{aligned}
$$

Tras este derroche inicial de confianza vinieron tiempos de tensión e incertidumbre; con todo, la prensa liberal siguió aprovechando el impacto simbólico del triunfo de Puebla

6 “Trofeos (Caricatura)", La Orquesta (14 mayo 1862). 
para fortalecer las convicciones republicanas entre el bando liberal. Pero las lentas movilizaciones castrenses abrieron un compás de espera que se reflejó en la caricatura política, misma que entabló una suerte de "guerra de desgaste" contra la imagen de los invasores, a los que no se dejaba de exhibir como aventureros de baja estofa marcados por el vicio y la decadencia física y moral.

Ejemplo de ello nos lo proporciona otra ilustración de Constantino Escalante publicada en La Orquesta a mediados de junio de 1862 [Imagen 3]. En ella, se ve a Lorencez parado sobre el lomo de un borrego para acceder a una ventana (con la leyenda México) con ayuda de una cuerda atada a la muñeca. En segundo plano vemos a Saligny - con cuernos y hojas de parra sobre la cabeza, a la manera de $\mathrm{Baco}$ - perdiendo la vertical, mientras derrama en el suelo el contenido de una copa. Al fondo se alcanzan a distinguir unas cajas con el rótulo Cognac. La caracterización de Saligny bajo la forma del dios romano del vino, reforzada por la copa y las cajas de licor, buscaba enfatizar la propensión del ministro francés a la ingesta de bebidas espirituosas que le atribuía, no sin cierto fundamento, la prensa liberal. ${ }^{7}$ Posiblemente, la intención de esta caricatura fuera exhibir a Saligny como la encarnación misma del vicio en un registro grotesco, con lo cual se deslegitimaría ante el público la empresa intervencionista en su conjunto.

Por otro lado, el borrego sobre el que Lorencez mantiene un precario equilibrio es una criatura aparentemente

\footnotetext{
7 Respecto a la asociación sistemática de Saligny con el alcoholismo, véase Barajas, La historia, pp. 205, 210 y 221. Véase también Acevedo, “Don Benito", pp. 15-53.
} 


\section{Imagen 3}

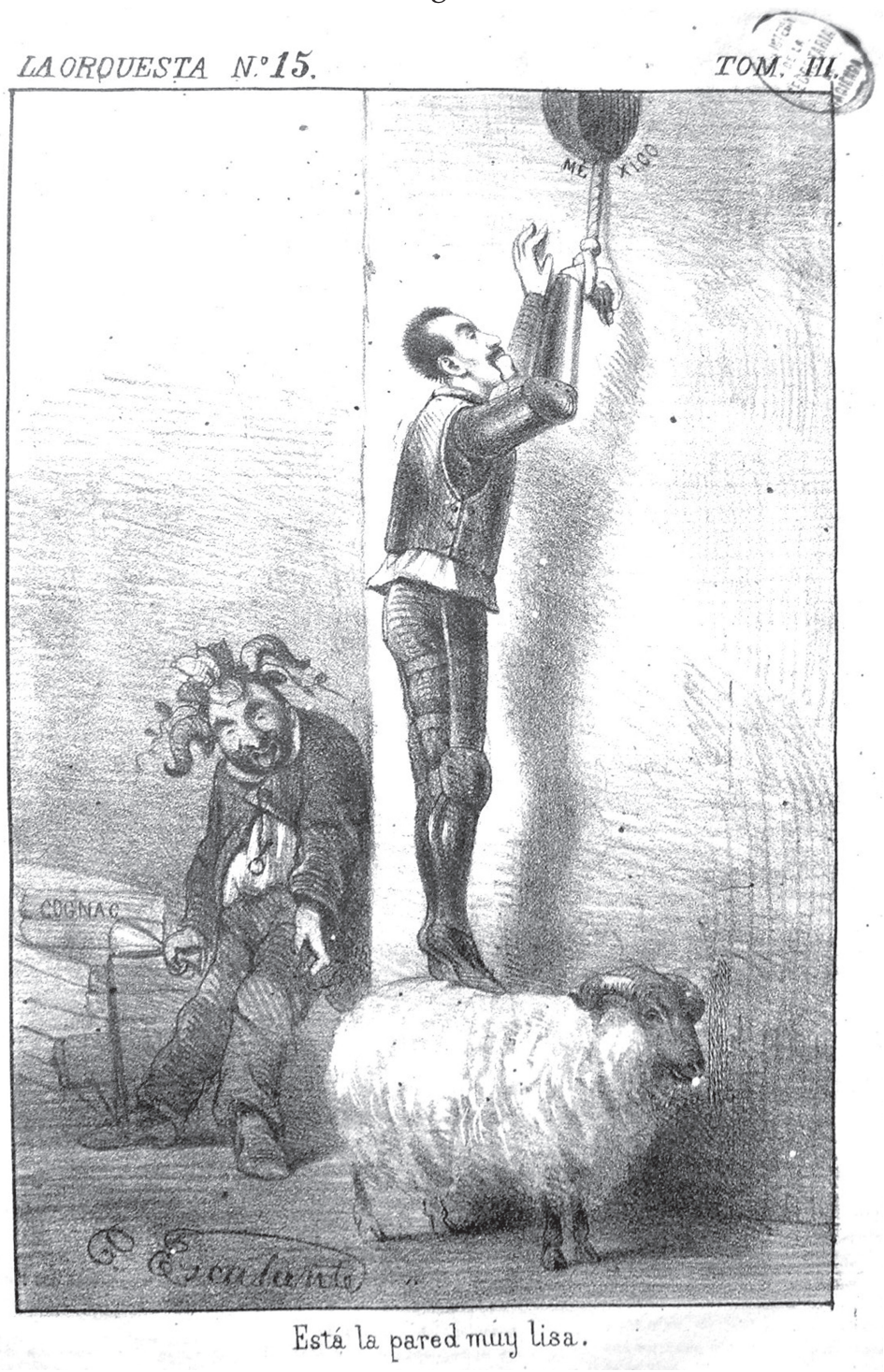

Constantino Escalante, "Está la pared muy lisa”, en La Orquesta (18 jun. 1862). 
inofensiva que se encuentra con frecuencia en la caricatura de la Intervención y el Imperio. La razón de esta presencia sostenida es que el bovino se constituyó como un arquetipo gráfico que representaba las noticias falsas y los rumores difundidos en la prensa como verdades, ${ }^{8}$ ya fuera por el beneficio económico o político - directamente, la lanaque iba de por medio en esta práctica, o por el escaso discernimiento que el fabulario atribuye tradicionalmente a la imagen del rebaño, guiado por la voluntad del pastor. En este caso, el borrego parece reforzar la idea de que el proyecto intervencionista estaba fundado en estratagemas y rumores difundidos por el bando intervencionista, que el público debiera tomar con cierta reserva. Pero la advertencia se hace extensiva al ejército invasor, pues el "borrego" no parece ser un sólido apoyo para el éxito de la empresa, sobre todo si se pretende escalar por una "pared muy lisa". ${ }^{9}$ De manera que, a los ojos del caricaturista, la intervención francesa no sólo es auspiciada por sujetos en grotesca decadencia moral, sino que, en consecuencia, funda sus expectativas de éxito en la triquiñuela y el engaño.

Los recursos que La Orquesta pone en juego para denostar al enemigo son vastos. Recurre a la ridiculización, la invectiva moral y la exaltación patriótica para escarnecer al invasor

\footnotetext{
8 Al respecto, apunta Barajas: “[...] Grupos y partidos tomaban a menudo esas noticias dudosas como verdades absolutas, y usaban la información para fijar posiciones y armar estrategias, lo que a la larga les resultaba catastrófico. A esos rumores, noticias falsas o dudosas se les llamaba 'borregos', por aquello de que los que las seguían iban por lana y salían trasquilados"; BARAJAs, La bistoria, p. 187.

9 Véase también "Está la pared muy lisa”, texto complementario a esta imagen, en La Orquesta (18 jun. 1862).
} 
y sus aliados convirtiéndolos en criaturas monstruosas y repugnantes. Así, apelando a la creación de un "Nuevo Zodiaco", representa a Saligny personificando al signo de Acuario, bajo la apariencia de una suerte de demonio alado, de ángel exterminador, que vierte su vómito alcohólico y el contenido de una botella de Cognac sobre el Tratado de la Soledad ${ }^{10}$ [Imagen 4]. Un texto complementario, publicado en el mismo número, dice: "Sol en Acuario. Dice el libro de los oráculos que el que nace bajo este signo será soberbio, inconstante y pendenciero. Que tendrá antojos estrafalarios y emprenderá cualquier cosa por salirse con la suya". ${ }^{11}$

Por su parte, representando al signo de Cáncer, Almonte es retratado bajo la forma de un cangrejo, emblema por antonomasia del conservadurismo, al menos desde mediados del siglo XIX, por su manera característica de andar hacia atrás, a contrapelo del progreso. ${ }^{12} \mathrm{El}$ cangrejo, de acuerdo con una tradición simbólica que se remonta a la antigüedad clásica, era considerado portador de la desgracia e incluso se asociaba con la enfermedad. ${ }^{13}$ Para la época que tratamos, la imagen del crustáceo constituía una alegoría política

${ }^{10}$ Acuerdo mediante el cual las fuerzas militares de España e Inglaterra, que en un inicio apoyaron la expedición imperial de Napoleón III, se retiraron del país, dejando en la campaña al ejército francés en solitario. 11 “Nuevo Zodiaco (caricatura)", La Orquesta (21 jun. 1862).

${ }^{12}$ Esta analogía política entre el conservadurismo y el cangrejo, también era utilizada en España y es factible que su empleo inicial se originara en la península Ibérica. Rico y Amat, en su Diccionario, publicado originalmente en 1855, asienta: "De algún tiempo a esta parte el cangrejo ha procreado de tal modo que son innumerables los que se arrastran por las playas del absolutismo; ;ay de los pobres cangrejos si se descuidan y llega a atraparlos alguna ola revolucionaria!” Cursivas en el original, p. 94. 13 Tal asociación se refiere concretamente al cáncer, de acuerdo con la medicina hipocrática, que posiblemente vinculaba al cangrejo con una 


\section{Imagen 4}

NS 16.

IVIEO ZODIACA.

T. IIt.

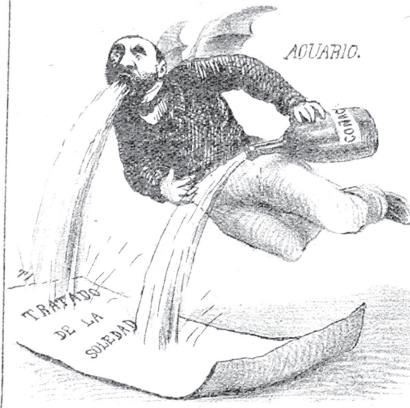

En vano vierie el infeliz acuario

Su comompida biel de mercenario.

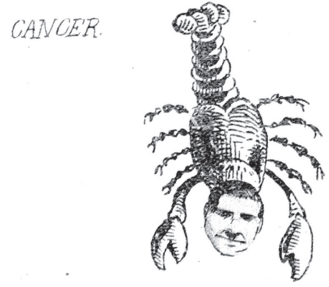

Gran Cancer es Aimonie ; Paiarata!

Un Cancer tan mum muncó nos rnata.

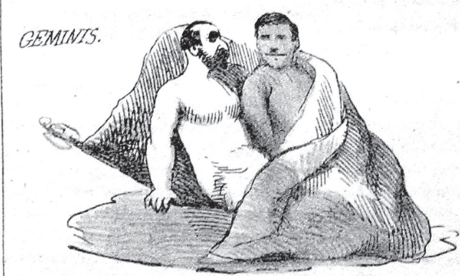

Es tan buena la mula, como el macho; Que Iriunfo Laurences; mas yo fe agrego: Than es um traidor ofro un horracho. "Mucha lana presentía ese borreve."

“Nuevo Zodiaco”, en La Orquesta (21 jun. 1862). 
bastante bien consolidada, fundada en la idea de retroceso con la que se le asociaba, participando con ello de una metáfora muy cara al liberalismo iluminista: la lucha de opuestos entre el progreso y el retroceso.

Durante la Guerra de Intervención, volvieron a tomar impulso las versadas y canciones que salieron a la luz durante la revolución de Ayutla, las cuales identificaban a los cangrejos con el partido conservador. Por ejemplo, las famosísimas coplas de "Los cangrejos", originalmente compuestas por Guillermo Prieto en 1854, fueron reutilizadas y actualizadas durante la invasión francesa. ${ }^{14}$ En el caso de esta caricatura, la apelación al zodiaco es solo un recurso visual para señalar con sorna la calidad moral de los enemigos de la República, vinculándolos a referentes monstruosos, ya fundándose en la imaginería religiosa del demonio alado que se cierne como una amenaza mortal, ya apelando a la tradición política liberal que asociaba al cangrejo con las fuerzas retardatarias, promotoras del retorno al antiguo régimen. El zodiaco, en tanto metáfora de los caprichosos tiempos políticos, continuaría siendo una rica fuente de inspiración para la caricatura política, aun después de la restauración de la República.

La entrada del ejército francés a la ciudad de México marcó el fin de la primera época de La Orquesta y sus colaboradores huyeron de la capital, tal como lo haría el gobierno republicano. Con la desaparición de este periódico, la causa

especie de "demonio de la enfermedad". Al respecto véase Biedermann, Diccionario, pp. 87-88.

${ }^{14} \mathrm{Al}$ respecto véase MendozA, “Algunas canciones”, pp. 27-28, así como el Cancionero. 
republicana perdió un importante espacio de expresión y propaganda. Asimismo, el triunfo del ejército napoleónico ocasionó nuevas limitaciones a la libertad de imprenta, sobre todo para las expresiones gráficas y escritas que apoyaban al gobierno republicano, de manera que, de acuerdo con lo que señala Rafael Barajas, la prensa liberal registró un sensible retraimiento en el número de publicaciones y su duración, a lo largo de $1863 .^{15}$

Sin embargo, por donde pasaba la República trashumante se fundaban periódicos adeptos al gobierno de Benito Juárez, que tenían un breve margen para expresarse por la letra o por la imagen. Tal es el caso del efímero periódico El Monarca, que se editó en San Luis Potosí mientras los poderes republicanos se asentaron en aquella ciudad. Este semanario, presumiblemente dirigido por Vicente Riva Palacio, contaba con la colaboración periodística de Guillermo Prieto e Ignacio Ramírez, mientras que a Melchor Álvarez y B. Ortiz correspondían las labores gráficas. Desde esa nueva trinchera periodística, la caricatura política continuó su desigual combate contra la Intervención, asumiendo una nueva estrategia que tuvo como nuevo objetivo de crítica a Napoleón III, dejando de lado por algún tiempo a los conservadores mexicanos. Una ilustración de Ortiz muestra al emperador de los franceses como un demonio que arrulla en brazos a Saligny [Imagen 5].

El ministro galo tiene el aspecto de un bebé, arropado por una frazada sobre la que se lee: Bonos Jecker; mientras que el demonio lleva sobre los cuernos las inscripciones 1848 y 2 de diciembre, en alusión a la llegada de Napoleón III a la

${ }^{15} \mathrm{Al}$ respecto véase BARAJAs, La historia, p. 76. 


\section{Imagen 5}

Eh MONAKCA. NO

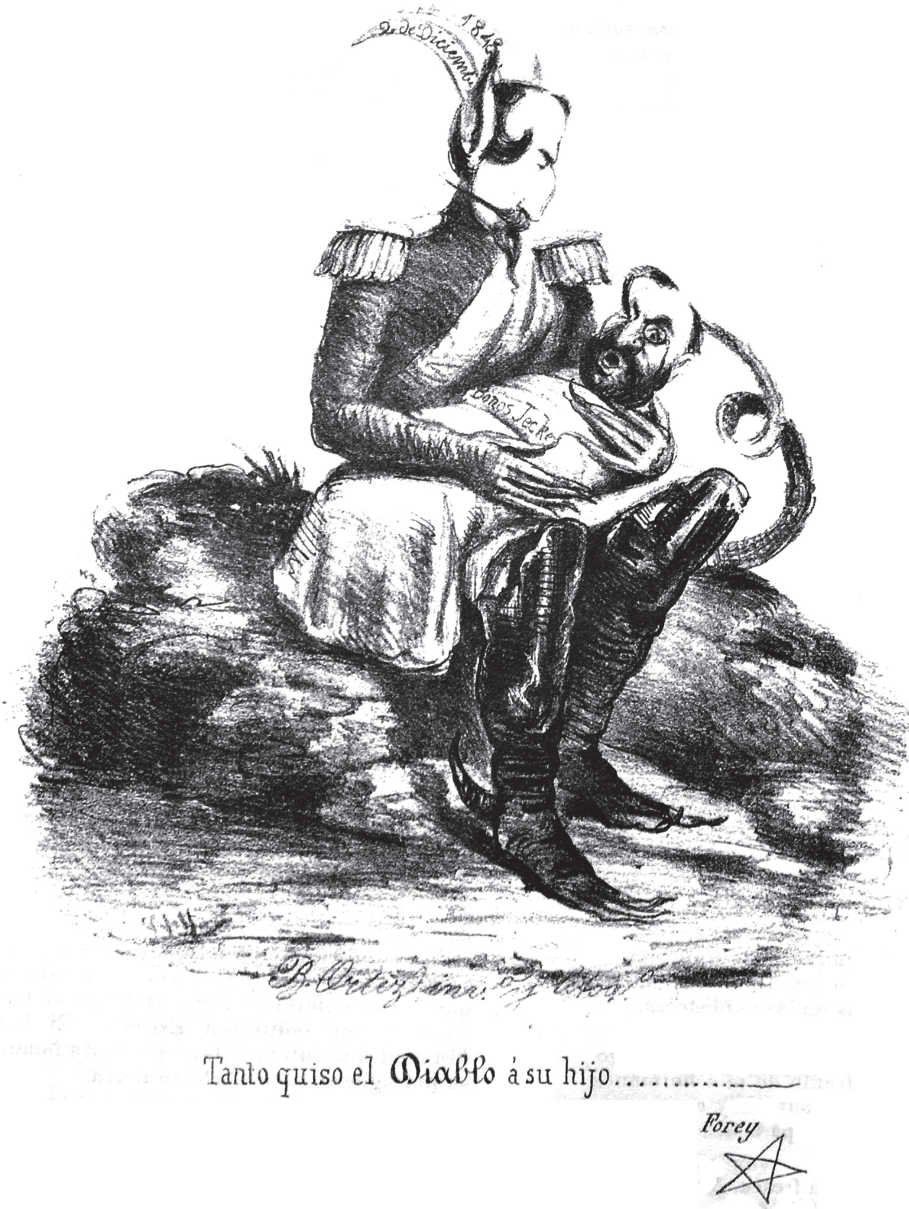

B. Ortiz, “Tanto quiso el diablo a su hijo...”, en El Monarca (11 oct. 1863). 
presidencia de Francia y a la fecha del golpe de estado por medio del cual se convirtió en emperador. Según se desprende de los versos que acompañaban la imagen en el periódico potosino, este emperador satánico intenta amamantar al ministro con ayuda de su larga y puntiaguda cola. ${ }^{16}$ Se trata, en suma, de una imagen tradicionalmente relacionada con el mal, que vincula el origen de la intervención francesa con una maquinación infernal. Bajo esta óptica, teñida de imaginería religiosa, Napoleón el Pequeño - como fuera bautizado por Victor Hugo - se representaba con la carga simbólica del adversario por excelencia del bien, que se ve burlado en la consecución de sus objetivos. Con ello, además del efecto cómico de la ridiculización del demonio (propio de la tradición popular y burlesca presente en las pastorelas), se buscaba facilitar la lectura política de la

${ }^{16}$ En el texto que complementa la imagen, vuelve a hacerse alusión chocarrera a la embriaguez del ministro francés. Véase "El rorro", en $E l$ Monarca (11 oct. 1863): "Tuvo el demonio tercero / un hijo que idolatraba / y aunque el muchacho era fiero, / para el tata era hechicero / y al verlo echaba la baba. // Mamaba el muchacho hambriento; / y como no tenía madre / que le aflojase el sustento, / hubo de darle alimento / hasta con la cola el padre. // En lugar de mamadera / le ponía la bota entera / de cognac o bien de rom [sic.], / de cerveza una caldera, / o de brandy un garrafón. // ¡Qué estómago de muchacho! / ¡Qué cabeza de borracho! / Nutrido con fuerte alcohólico / jamás lo atacó ni un cólico / jamás lo aventó un empacho. // Aunque el padre es muy adusto, / viendo a su nene robusto / goloso, gritón simpático, / lo vistió de diplomático / y estaba loco de gusto. // Mas bufaba la criatura / con aquella vestidura; / la ensució de arriba abajo, / y el papa tuvo el trabajo de / de volverlo a su envoltura. // Pero el nene continuaba / ahuyando [sic.] cual perra brava, / y el tata con gran cariño / cantando el arrorro niño / en sus brazos lo arrullaba. // Sacudiéndolo a su antojo / por poco lo deja cojo, / y con tanto amor, de fijo, / tanto le hizo el diablo a su hijo que al cabo le sacó un ojo [...]”. 
ilustración, procurando que el enemigo fuera identificado a primera vista.

Finalmente, Maximiliano llegó a México. Una vez establecido el nuevo monarca y formalizado, en la medida de lo posible, el gobierno imperial, fue reinstaurada la libertad de imprenta con algunas restricciones. Así, en 1864 reapareció La Orquesta. Aunque no renunció a sus principios políticos, el periódico sí modificó ligeramente su línea editorial, quizá con la finalidad de evadir los mecanismos de la censura. De esta manera, evitó la confrontación directa con el nuevo gobierno y se centró más bien en la crítica a los conservadores mexicanos, celebrando los reveses que el propio emperador les propinaba, a la vez que mantenía una respetuosa distancia respecto a la figura del gobernante.

El proyecto imperial no tardó en evidenciar sus fisuras, pues cada vez se hacía más notorio que las aspiraciones de Napoleón III, las de los conservadores mexicanos y las del propio Maximiliano, iban en distintas direcciones. Las opiniones aparentemente progresistas del archiduque causaban cierta incomodidad entre sus partidarios nacionales, y esto fue captado por la mirada mordaz de La Orquesta, que no dejaba de señalar las frustradas aspiraciones aristocráticas de los conservadores locales, así como la propensión acomodaticia de la nueva clase política que medraba bajo los auspicios del imperio.

En este sentido, la crítica expresada por medio de la caricatura se cebó en la clase política vinculada al conservadurismo, identificada como el principal objeto de escarnio en el combate al imperio. Por ejemplo, en La Sombra ${ }^{17}$ se

${ }_{17}$ Periódico jocoserio, ultraliberal y reformista. Escrito en los antros de 
caracterizaba a la clase política como un estamento constituido por lobos que sólo miraban por sus propios intereses. En una viñeta publicada a principios de 1865 [Imagen 6], muy probablemente inspirada en la obra del caricaturista francés Grandville [Imagen 7], se ve a dos lobos sosteniendo una enigmática conversación en la que se trasluce un ánimo de especulación sobre el futuro político; ${ }^{18}$ los dos caninos aparecen antropomorfizados, con levitas y sombreros de copa. El sentido de la imagen parece verse reforzado por la insinuación de una sentencia política recurrente a lo largo del siglo xIx: "Dos lobos no se muerden”.

Aunque el texto que acompaña la ilustración se titula "Dos...", los puntos suspensivos acaso sugieran que el contenido de la máxima era sobradamente conocido en una comunidad de lectores afecta a la prensa política. En apoyo de esta hipótesis podemos decir que la similitud compositiva entre esta viñeta y la ilustración de Grandville, justamente titulada "Les Loups ne se mangent pas entre eux", ${ }^{19}$ es expresión de un tema político ya conocido en las producciones gráficas nacionales, pues ya en 1851, en La Ilustración Mexicana, se publicó una imagen -idéntica también a la de Grandville - titulada "Dos lobos no se muerden", 20 en alusión fabulesca a que dos personas de similar condición con idénticos intereses no pueden hacerse daño. Esta

la tierra por una legión de espíritus que dirigen Mefistófeles y Asmodeo. 18 “- ¿'Sí o no? / - Sí y no. / - Las dan? / - No creo... / - Nos las vuelven? / - Parece que no. / - Nos quedamos sin ellas? / - Creo que sí / - Nos rehacemos? / - No trae instrucciones. / - ¡Santa Bárbara! / - Conque las fincas... / - ¡Chitón! / - ¡Chitón!”

${ }^{19}$ Literalmente: "Los lobos no se comen entre ellos".

${ }^{20}$ Imagen 42. Véase CASTro (coord.), Tipos y caracteres, p. 358. 
Imagen 6

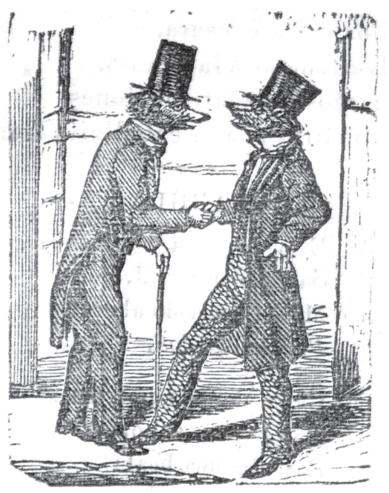

DOS.....

La Sombra (6 ene. 1865).

Imagen 7

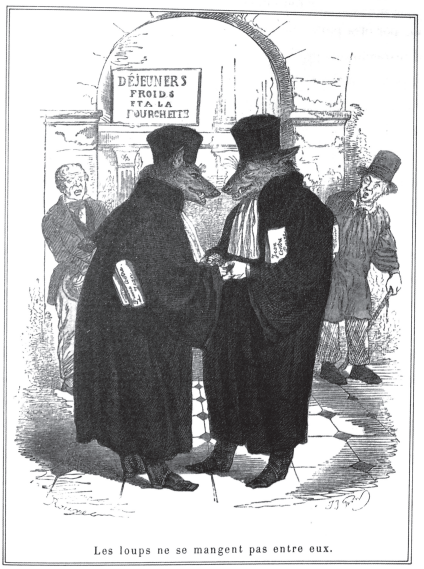

Grandville, "Les loups ne se mangent pas entre eux", Scénes de la vie privée et publique des animaux (ca. 1842). 
máxima, o su paráfrasis, seguiría siendo utilizada en la caricatura política a principios del siglo xx para referirse a la amenaza y la voracidad encarnadas en una clase política dispuesta a la defensa de sus intereses a cualquier costo.

Sin embargo, durante el Segundo Imperio, la figura animal más socorrida para representar el talante retardatario de la clase política nacional seguiría siendo el cangrejo. Así lo vemos en una suerte de emblema de la situación nacional [Imagen 8] constituido por una curiosa alegoría del comercio y la industria que va sobre un carro, jalando a un hombre que lleva a cuestas un nivel arquitectónico, símbolo francmasónico de la igualdad y el equilibrio. Arrastrándose tras este hombre, dificultando su marcha, se ve un cangrejo con cabeza humana; en su indumentaria aristocrática lleva las inscripciones Pájaro Verde y La Sociedad, ${ }^{21}$ en alusión a los más representativos periódicos conservadores, contra los que se orientaban las críticas de la prensa liberal partidaria de la República. En conjunto, la imagen parece representar el estado anómalo de la situación política nacional, en la que, siguiendo la interpretación liberal, el lastre de los conservadores impide el progreso de México al tiempo que tensa la situación provocando el desequilibrio nacional. En el texto que complementa el sentido de esta caricatura se lee:

El retroceso, fiel siempre con sus principios, ha de minar la estabilidad del país durante las altas horas de la noche, y cuando todos los vivientes se entregan al reposo, porque el retroceso, como las aves nocturnas, buscan las sombras y el misterio para

21 Sobre los avatares de estos dos periódicos, sus redactores, directores y colaboradores, véase Castro y Curiel (coords.), Publicaciones, pp. 419$432,551-561$. 


\section{Imagen 8}

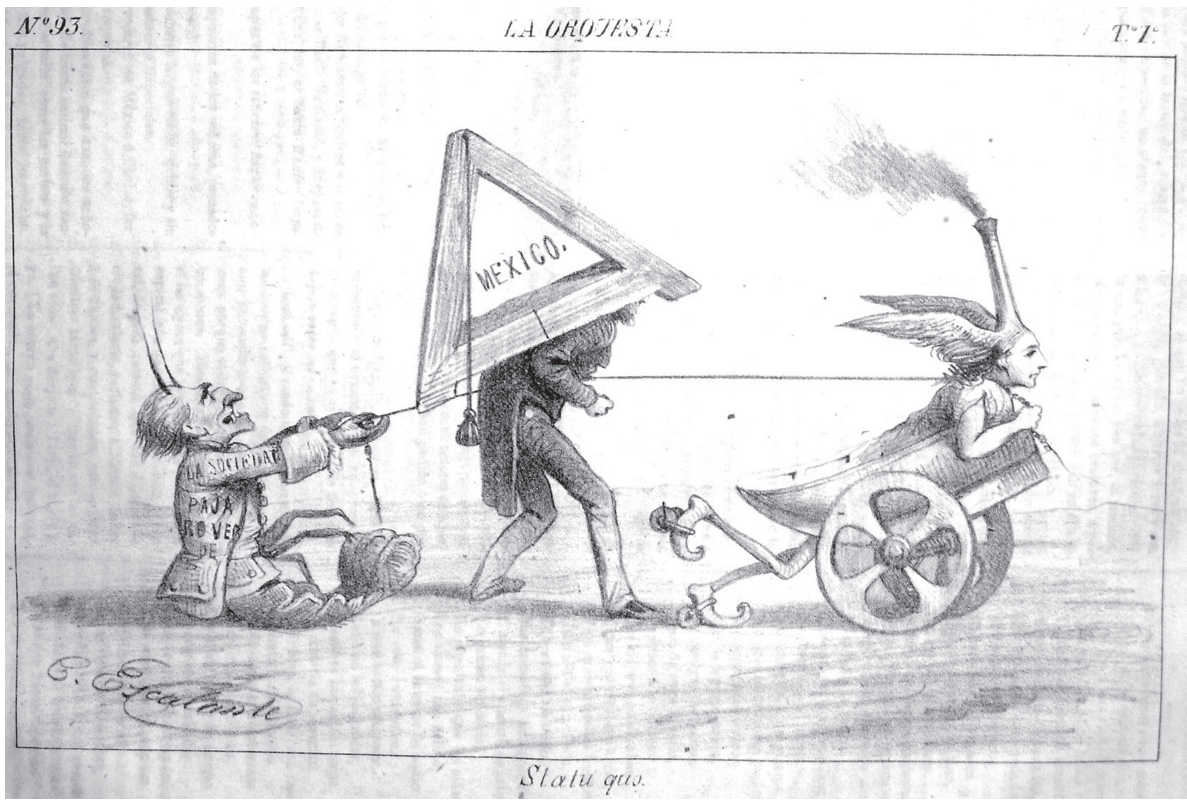

Constantino Escalante, "Statu quo", en La Orquesta (21 oct. 1865). 
hacer sus presas, saboreando después en sus madrigueras el éxito de sus empresas. ${ }^{22}$

Pareciera que el cangrejo del conservadurismo no sólo encarna una fuerza retardataria de aspiraciones patéticas, que no es sólo la caracterización más o menos bufa de un sector político vinculado al poder, sino que además representa cáusticamente al "retroceso" en sí mismo, entendido como un orden de cosas contrario al bienestar de la nación; en esa medida, se convierte más en una criatura monstruosa que encarna una amenaza para la estabilidad política, al perpetuar un orden inicuo.

En el registro caricaturesco es frecuente encontrar esta ambivalencia entre lo bufo y lo amenazante. De manera que la imagen del cangrejo, empleada en el lenguaje gráfico como sinónimo del conservadurismo y de la colaboración con la administración imperial, en repetidas ocasiones fue objeto de este tratamiento dual. Por ejemplo, en una caricatura publicada en El Bertoldino a mediados de $1865,{ }^{23}$ vemos a un personaje de tez morena, vestido con larga blusa y pantalón oscuro - acaso una alegoría del pueblo mexicano - ${ }^{24}$ que con la ayuda de un látigo mantiene a raya a un trío de cangrejos con cabezas humanas. Sobre sus cuerpos llevan inscritos los títulos de los periódicos conservadores

22 Anónimo. “Statu quo (Caricatura)”, en La Orquesta (21 oct. 1865). Es digna de notarse la recurrencia a la nocturnidad como un elemento de repudio al enemigo, siguiendo la clave iluminista ampliamente desarrollada en el imaginario anticlerical.

23 Utilizo en este caso la fecha que proporciona BARAJAs, La historia, p. 236.

${ }^{24}$ La indumentaria de este personaje guarda cierta similitud con la caracterización de la vestimenta de los obreros europeos durante el siglo XIX. 
favorables al imperio, lo cual permite identificar a los personajes representados: El Cronista (Niceto de Zamacois), El Pájaro Verde (Mariano Villanueva y Francesconi) y Doña Clara (Miguel Piña). ${ }^{25}$ [Imagen 9]

La imagen, a partir del emblema político del cangrejo, además de proporcionar un retrato grotesco de la prensa conservadora, enfatiza una vez más la amenaza del retroceso que representaba la prensa favorable al imperio para el imaginario republicano. La presencia de esa suerte de alegoría del pueblo mexicano en actitud beligerante refuerza el sentido de confrontación, señalando al enemigo político como un peligro que es necesario conjurar.

Poco menos de un año antes de la caída del Imperio, en una caricatura de Escalante, volvemos a encontrarnos con el arquetipo del cangrejo en alusión a la prensa conservadora [Imagen 10], ${ }^{26}$ esta vez en un registro festivo y formando parte de una composición zodiacal en la que se representa el caprichoso signo de los tiempos políticos del ocaso del imperio. En la imagen, próxima a la sátira de costumbres, podemos ver a un cangrejo que entre sus tenazas lleva sendos ejemplares de El Pájaro Verde y El Ranchero de Matamoros. El crustáceo - acompañado de Juan Suárez y $\mathrm{Navarro}^{27}$ transfigurado en el grifo del escudo de los Habsburgo, del buevo buero del proyecto imperial (del que

${ }_{25}$ Respecto a Doña Clara y El Cronista véase Castro y Curiel (coords.), Publicaciones, pp. 226-231, 259-260.

${ }^{26}$ Se trata de una ilustración original de Grandville adaptada al contexto nacional [Imagen 11]

27 Encargado de la oficina de bienes eclesiásticos durante el imperio de Maximiliano. 


\section{Imagen 9}

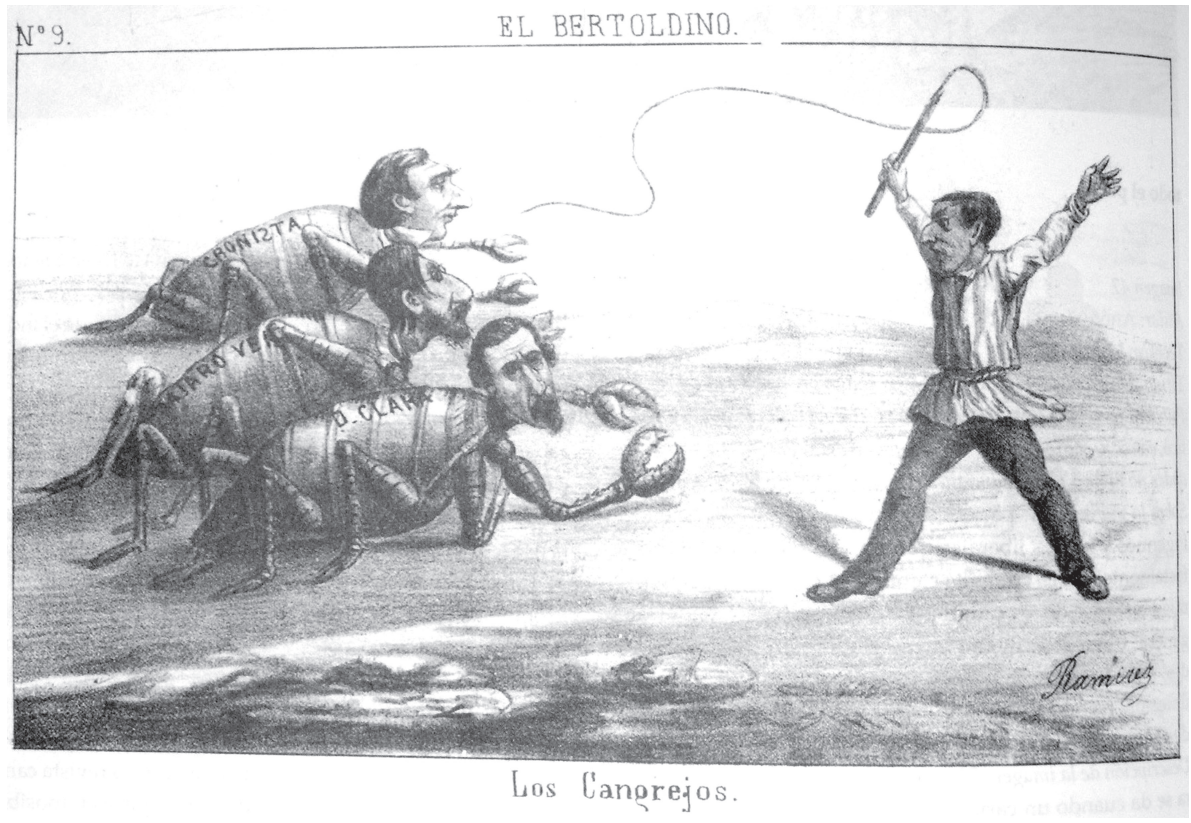

Ramírez, “Los cangrejos”, en El Bertoldino (1865). 


\section{Imagen 10}

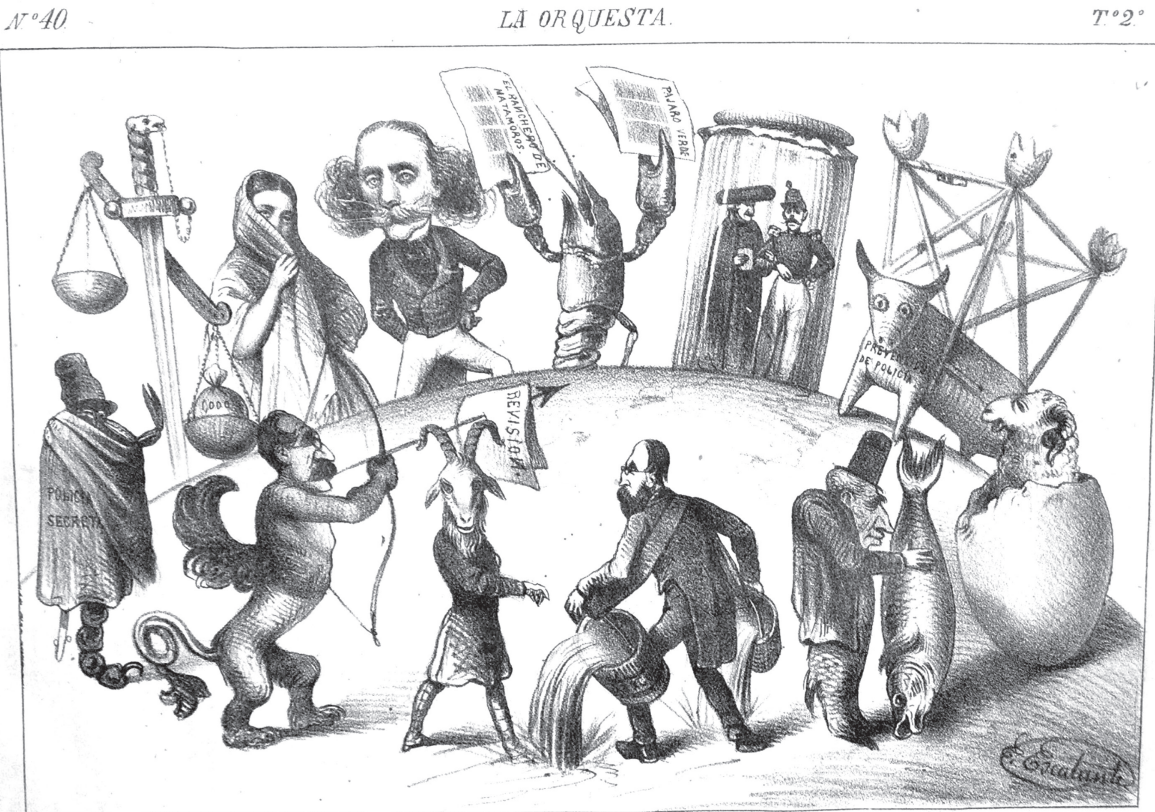

Los signos del Todiaco.

Constantino Escalante, “Los signos del Zodiaco”, en La Orquesta (19 mayo 1866). 


\section{Imagen 11}

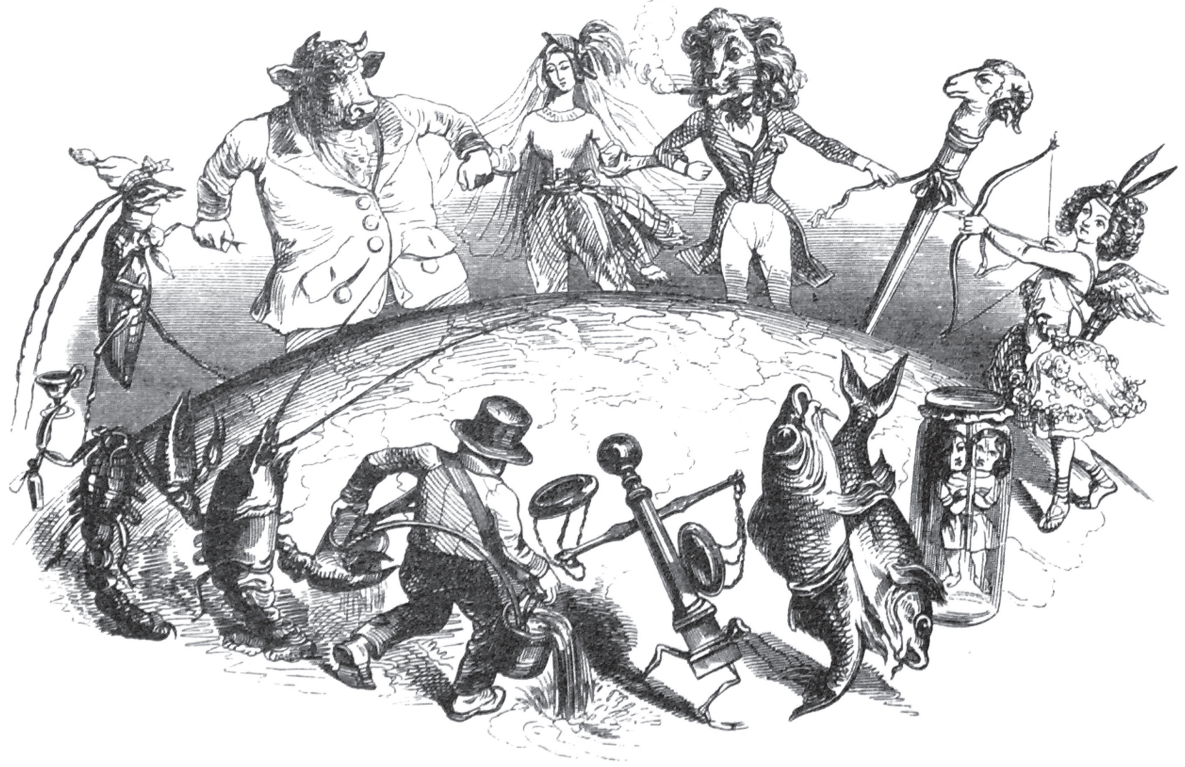

Grandville, Un autre monde... (1844). 
emerge un borrego), de Sebastián Pane ${ }^{28}$ caracterizado como pez, del escorpión de la Policía secreta, de la balanza desigual de la justicia, de un cura y un militar siameses conservados en un frasco, entre otras criaturas - se integra a un paisaje delirante en el que campea el conservadurismo de la política nacional. Se trata, en última instancia, de una imagen cargada de sorna de la sociedad imperial, en la que se representan de forma ridícula los valores contrarios al ideario liberal como una manera de resistencia al imperio, una discreta venganza en espera de mejores tiempos para la República.

\section{REFERENCIAS}

Acevedo, Esther

"Don Benito bajo la lente de los caricaturistas", en Esther Acevedo (coord.), Juárez bajo el pincel de la oposición, México, Universidad Autónoma Benito Juárez de Oaxaca, Secretaría de Hacienda y Crédito Público, 2006.

Barajas, Rafael

La bistoria de un país en caricatura. Caricatura mexicana de combate, 1829-1872, México, Conaculta, 2000.

Bassols, Ángel et al.

Temas y figuras de la Intervención, México, Sociedad Mexicana de Geografía y Estadística, Sección de Historia, 1963.

Biedermann, Hans

Diccionario de símbolos, Barcelona, Paidós, 1993.

${ }^{28}$ Propietario de la alberca del mismo nombre y entusiasta promotor de los baños como método curativo. 


\section{Cancionero}

Cancionero de la Intervención Francesa, México, Instituto Nacional de Antropología e Historia, Conaculta, Ediciones Pentagrama (Fonoteca del INAH, 13), 2002.

Castro, Miguel Ángel (coord.)

Tipos y caracteres: la prensa mexicana (1822-1855), México, Universidad Nacional Autónoma de México, 2001.

Castro, Miguel Ángel y Guadalupe Curiel (coords.)

Publicaciones periódicas mexicanas del siglo XIX, México, Universidad Nacional Autónoma de México, 2003.

GrandVille, Jean-Jacques

Un autre monde, París, H. Fournier Libraire Editeur, 1843.

Mendoza, Vicente T.

"Algunas canciones y sátiras durante la Intervención y el Imperio”, en BAssols et al., 1963.

Rico y Aмat, Juan

Diccionario de los politicos. Para divertimento de los que ya lo ban sido y enseñanza de los que aún quieren serlo, México, Miguel Ángel Porrúa, 1990.

Hemerografía

El Monarca. Periódico soberano y de origen divino. San Luis Potosí, S. L. P., 1863.

La Orquesta. Periódico omniscio, de buen bumor y con caricaturas, México, 1861-1867.

La Sombra, México, 1865. 